\title{
Restriction endonuclease profiles of mitochondrial DNA and the origin of the B genome of bread wheat, Triticum aestivum*
}

\author{
Dan Graur, $\dagger$ \\ Maia Bogher $\ddagger$ and \\ Adina Breiman $\$$
}

\author{
$\dagger$ Department of Zoology, George S. Wise Faculty of \\ Life Science, Tel Aviv University, Ramat Aviv 69978, \\ Israel. \\ $\ddagger$ Department of Botany, George S. Wise Faculty of \\ Life Science, Tel Aviv University, Ramat Aviv 69978, \\ Israel.
}

In an attempt to identify the donor of the $B$ genome in the emmer (AABB) and dinkel (AABBDD) wheats (Triticum turgidum and $T$. aestivum, respectively), the restriction endonuclease profiles of two regions around the mitochondrial cytochrome oxidase subunit I gene were compared with those of five putative diploid ancestors belonging to the Sitopsis section of the Aegilops genus: Ae. longissima, Ae. speltoides, Ae. bicornis, Ae. sharonensis and Ae. searsii. The mitochondria of the diploid donors of genome A ( $T$. monococcum, section Monococca) and genome D (Ae. squarrosa, section Vertebrata) were also tested. The results indicate that none of these diploid species is likely to have either donated the B genome or to be closely related to the donor. The restriction fragment patterns of $T$. turgidum and $T$. aestivum were identical, supporting the hypothesis that $T$. turgidum is the immediate maternal relative of $T$. aestivum. The restriction endonuclease profiles of $T$. monococcum var. boeoticum and $T$. $m$. var. urartu were also identical supporting their conspecific systematic assignment. No real taxonomic distinction exists between $T$ riticum and Aegilops. With the possible exception of Ae. longissima, the mitochondria of the Sitopsis section constitute a natural clade. Ae. speltoides shows high levels of mitochondrial polymorphism between accessions.

\section{INTRODUCTION}

Interest in the wild relatives of cultivated food crops has been aroused because of the dangers associated with genetic uniformity, and the potential use of wild genetic varieties for diversifying the genetic pool (Zohary, 1983). Bread wheat, Triticum aestivum, and macaroni wheat, $T$. turgidum var. durum, are two of the oldest and most widespread food crops under domestic cultivation (Helbaek, 1959; Jenkins, 1966; Morris and Sears, 1967; Zohary, 1965, 1983). Starting with Alphonse de Candolle's somewhat imaginative Origine des Plantes Cultivées (1883), the evolutionary histories of these wheats and their putative wild relatives have been subjected to extensive research and speculation. Most researchers agree that the Middle East was the geographic centre of domestication and genetic diversification of Triticum, as

\footnotetext{
* Dedicated to the memory of two pioneers of wheat research, Aaron Aaronsohn (1876-1919) and Hitoshi Kihara (18931986).
}

well as other cultivated crops, such as Hordeum (barley), Secale (rye) and Avena (oats) (Harlan and Zohary, 1966; Anikster and Wahl, 1979). In 1906, Aaron Aaronsohn discovered the wild emmer wheat, Triticum dicoccoides, in the Upper Galilee (Aaronsohn, 1906, 1909). This dicoccoides variety, currently referred to as Triticum turgidum var. dicoccoides (Korn.) Thell., was nicknamed by Aaronsohn "Em Ha Khita", Hebrew for Motherof-Wheat, an etymology which proved quite accurate in view of modern molecular knowledge.

Both Triticum and Aegilops belong to the family Gramineae. Beyond this rough assignment, however, considerable disagreement pervades wheat taxonomy (for a review, see Kimber and Sears, 1983). Sakamura (1918) and Kihara $(1919,1924)$ were the first to recognize that Triticum species constitute a three-level ploidy series, with the einkorn group, e.g., T. monococcum, containing 14 chromosomes, the emmer group, e.g., $T$. turgidum, containing 28 chromosomes, and the dinkel group, e.g., $T$. aestivum, containing 42 chromosomes. Moreover, Kihara (1924) provided 
the first evidence which indicated that the tetraploid emmers and the hexapolid dinkels are allopolyploids, i.e., each chromosome set is genetically distinct, having probably originated from different wild diploid species. The genome that is common to Triticum aestivum, $T$. turgidum and $T$. monococcum was designated genome $\mathrm{A}$. The other genome of $T$. turgidum, which also exists in $T$. aestivum, was designated $\mathrm{B}$. The third genome of the dinkel group was designated D. Thus, Triticum aestivum has an AABBDD genomic constitution. Wild species of Aegilops are known to contain other haplotypic genomic sets as well, e.g., genome $\mathrm{C}$ in Ae. caudata, and genome $\mathrm{M}$ in Ae. comosa and Ae. heldreichii.

The problem of reconstructing the phylogeny of bread wheat, Triticum aestivum, can essentially be reduced to (1) determining the origin of each of the three genomes (A, B and D), and (2) elucidating more ancient phylogenetic relationships between these genomes. The immediate tetraploid maternal ancestor of $T$. aestivum is in all likelihood a wild or a cultivated form of $T$. turgidum (AABB), the female gamete of which formed a hybrid with a male gamete of Aegilops squarrosa (DD), resulting in the present AABBDD genomic constitution (Kihara and Lilienfeld, 1951; Kerby and Kuspira, 1987). In this sense, Aaronsohn's original designation of the wild emmer wheat, T. turgidum var. dicoccoides, as the Mother-of-Wheat is correct. In the same vein, Kihara's Aegilops squarrosa should be designated the Father-of-Wheat.

The phylogeny of wheat becomes less clear, however, as we look for more ancient genomic ancestors. Although there is ample evidence that Triticum monococcum (AA) is the source of the A genome in both bread and macaroni wheats, and is the closest paternal relative of $T$. turgidum and T. aestivum (Gill and Kimber, 1974; Fernandez de Caleya et al., 1976; Jones et al., 1982; Kerby and Kuspira, 1987), there is little agreement in the literature in regard to the origin of the B genome. The only thing that can be stated with some certainty is that the donor of the B genome is also the donor of the cytoplasmic components of both tetraploid and hexaploid wheats, i.e., the B donor is the Grandmother-of-Wheat (Maan and Lucken, 1967, 1971; Chen et al. 1975; Vedel et al., 1978; Hirai and Tsunewaki, 1981). Fig. 1 summarizes the consensual view on the origin of the three genomes in bread wheat.

On the basis of different methodologies, several diploid species have been proposed as putative donors of the $\mathrm{B}$ genome. The most prominent of

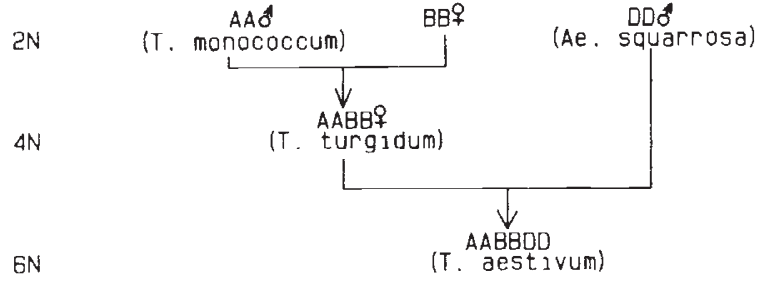

Figure 1 Schematic representation of the genomic phylogeny of hexaploid bread wheat.

these "suspects" are members of the Sitopsis section of the Aegilops genus: Ae. bicornis (Sears, 1956), Ae longissima (Vittozi and Silano, 1976; Gerlach et al., 1978; Tsunewaki and Ogihara, 1983), Ae. searsii (Feldman, 1978), Ae. sharonensis (Kushnir and Halloran, 1981), and Ae. speltoides (Sarkar and Stebbins, 1956; Riley et al., 1958; Rees and Walters, 1965; Jaaska, 1978). In particular, Ae. speltoides, Ae. longissima and Ae. bicornis are given prominence as putative donors of the $\mathrm{B}$ genome since they are indistinguishable from $T$. turgidum as judged by morphological and physiological properties (Tsunewaki and Ogihara, 1983). $T$. monococcum var. urartu, a member of the Monococca section of the genus Triticum, has also been suggested as an ancestor (Johnson, 1972, 1975).

The purpose of this work was to find out which, if any, of the above suspects is the wild donor of the B genome. Since we are in fact searching for a maternal ancestor twice removed from bread wheat, and since the genomic material in cytoplasmic organelles is exclusively maternal, we decided to reconstruct the phylogeny of bread wheat by using restriction endonuclease profiles of mitochondrial DNA.

\section{MATERIALS AND METHODS}

The following species and cultivars were used: hexaploid wheat, Triticum aestivum var. aestivum (accession numbers 01 and 08); tetraploid wheat, T. turgidum var. dicoccoides (17); diploid species, Aegilops sharonensis (02), Ae. longissima (01,09), Ae. searsii (16), Ae. bicornis (01), Ae. speltoides (01, 05, 08), T. monococcum var. urartu (T. urartu) (04), T. m. var. boeoticum ( $T$. boeoticum) (02), and Ae. squarrosa (T. tauschii) (01,27). Accession numbers and plants were kindly provided by Dr. M. Feldman, Weizmann Institute of Science, Rehovot, Israel.

Preparation of total DNA and mitochondrial DNA, restriction endonuclease digestions, 


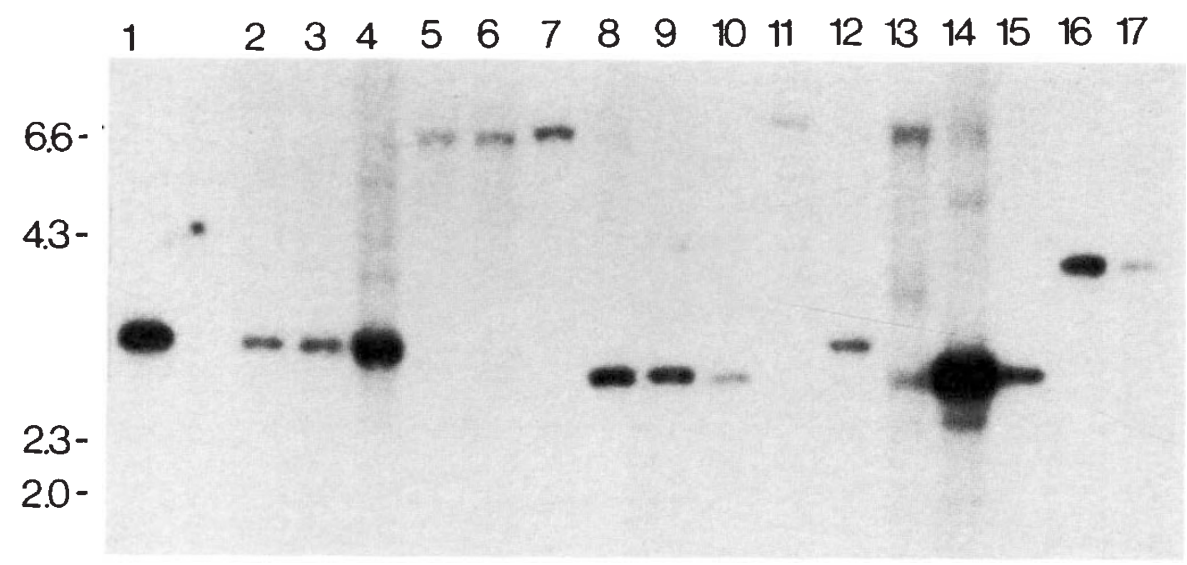

Hind III $/ 5^{\prime} \operatorname{coxI}$

Figure 2 Autoradiograph of Southern blots from total DNA of cultivated and wild wheat species. Slot designations: $1=$ Triticum aestivum (01, mitochondrial DNA), $2=T$. aestivum (01, total DNA), $3=T$. aestivum $(08), 4=T$. turgidum, $5=T$. monococcum var. urartu, $6=T$. monococcum var. boeticum (02), $7=T$. monococcum var. boeticum (03), $8=$ Aegilops sharonensis, $9=$ Ae. searsii, $10=$ Ae bicornis, $11=$ Ae. speltoides $(01), 12=$ Ae. speltoides $(05), 13=$ Ae. speltoides $(08), 14=$ Ae. longissima $(01), 15=A e$. longissima $(09)$, $16=$ Ae. squarrosa (01), $17=$ Ae. squarrosa (27).

Southern blot hybridizations and preparation of recombinant DNA clones were carried out according to Breiman (1987). Samples of total DNA $(10 \mu \mathrm{g})$ were digested for $16 \mathrm{~h}$ with one of three six-base endonucleases: BamHI, HindIII and EcoRI. In one case ( $T$. aestivum, accession number $01)$, an additional sample of mitochondrial DNA $(1 \mu \mathrm{g})$ was digested for $6 \mathrm{~h}$. The restricted DNA from each sample was hybridized to one of two mitochondrial probes: L4c $\left(5^{\prime} C O X \mathrm{I}\right)$ and $\mathrm{Q} 2 \mathrm{e}$ $\left(3^{\prime} C O X I\right)$. L4c $\left(5^{\prime} C O X I\right)$ is a HindIII-Pst I fragment, $900 \mathrm{bp}$ in length, containing the $5^{\prime}$ end and flanking region of the gene encoding subunit I of the mitochondrial cytochrome oxidase. Q2e $\left(3^{\prime}\right.$ COXI) is a TaqI-Sau3a fragment, $240 \mathrm{bp}$ in length, containing a $3^{\prime}$ sequence within the cytochrome oxidase subunit I gene. Both probes were cloned in M13, and were kindly provided by $\mathrm{Dr}$ L. Bowen, Department of Biology, University of Ottawa, Canada.

\section{RESULTS AND DISCUSSION}

Consistent with the results of Breiman (1987) we find that the two probes used in this study detect specific mitochondrial DNA sequences in total DNA preparations. We obtained identical hydridization profiles for both mitochondrial DNA and total DNA digests. An autoradiograph of Southern blot hybridizations of DNA digested with HindIII and hybridized with the L4c probe is shown in fig. 2. One can see, for instance, that lane 1 containing mitochondrial DNA from $T$. aestivum is indistinguishable from lane 2 containing total DNA digests. This shows that for these probes, hybridization with promiscuous DNA (Stern and Lonsdale, 1982) is either nonexistent or that it is below the level of detection so that it does not affect our results.

The restriction fragment length distribution in each species is given in table 1 . From the hybridization profiles we could infer 25 restriction fragments, only one of which was common to all species. (All mitochondrial specimens resulting from the EcoRI-Q2e treatment were monomorphic for a $1.9 \mathrm{~kb}$ fragment.) T. aestivum and T. turgidum yielded identical hybridization patterns, supporting the hypothesis that $T$. turgidum is the immediate maternal ancestor of $T$. aestivum. The restriction endonuclease profiles of the two $T$. monococcum subspecies, urartu and boeoticum, are indistinguishable, supporting their conspecific systematic assignment, rather than their classification as two separate species ( $T$. urartu and T. boeoticum).

Since we could not physically map the restriction sites, the number of nucleotide substitutions per site (d) was estimated by using the restriction fragment data according to Nei and Li's (1979) length-difference method. The values of $d$ are given in table 2. For the range of $d$ values obtained in this study, Nei and Li's method yields fairly accurate results (Nei 1987, p. 107). These values were 
Table 1 Restriction fragment-length patterns of Triticum and Aegilops total DNA digests hybridized with radioactively labelled plasmids containing the $\mathrm{L} 4 \mathrm{c}$ and $\mathrm{Q} 2 \mathrm{e}$ sequences

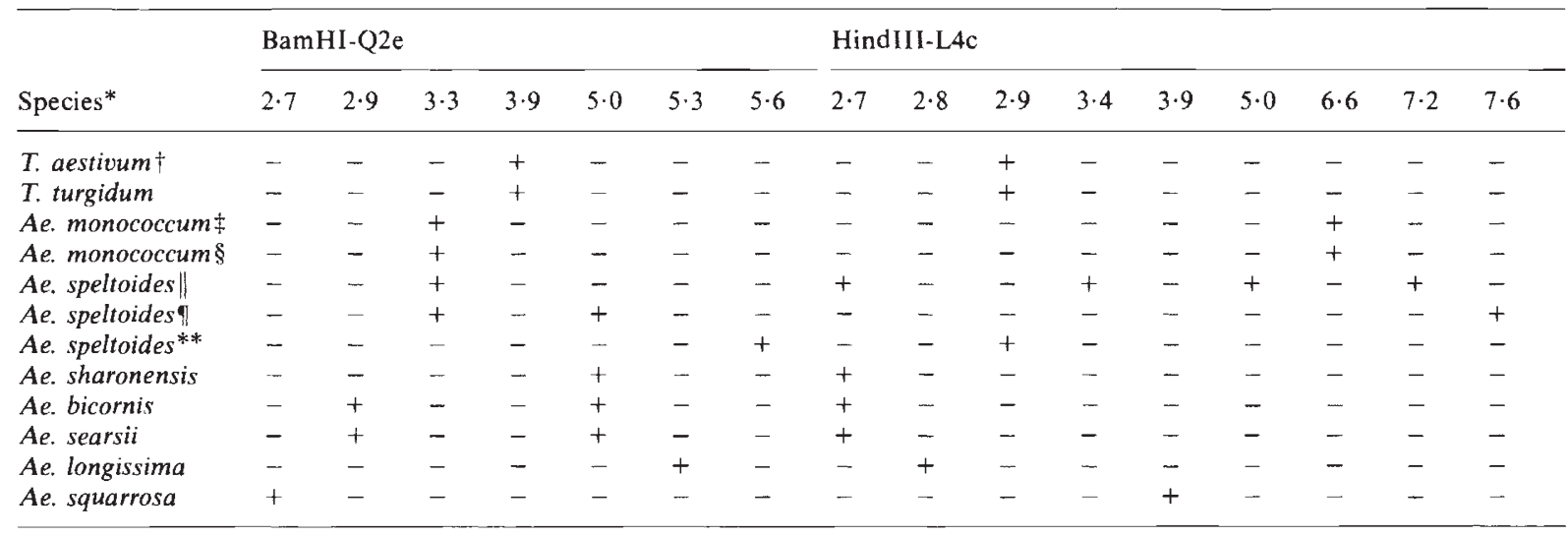

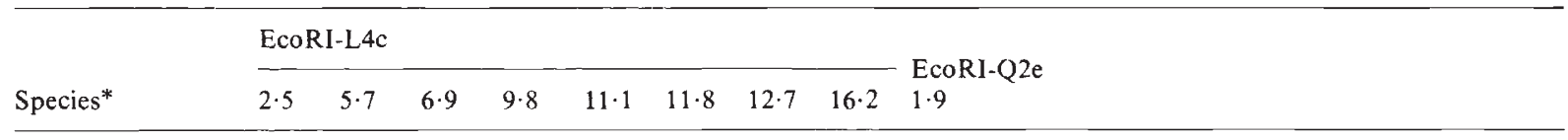

T. aestivum $\dagger$

T. turgidum

Ae. monococcum

Ae. monococcum $\S$

Ae. speltoides $\|$

Ae. speltoides

Ae. speltoides**

Ae. sharonensis

Ae. bicornis

Ae. searsii

Ae. longissima

Ae. squarrosa

* With the exception of Ae. speltoides, all accessions within each species yielded identical hybridization patterns.

$\dagger$ Same hybridization patterns were obtained with both mitochondrial and total DNA digests.

$\ddagger$ var. urartu.

$\S$ var. boeticum.

\| Accession number 08.

I Accession number 01 .

**Accession number 05 .

Table 2 Matrix of the number of nucleotide substitutions per site (d) between Triticum and Aegilops species. Values of d were estimated according to the method of Nei and $\mathrm{Li}$ (1979). Species numbers are as in table 1. Lower half $=$ observed $\mathrm{d}$ values, upper half = estimated $d$ values by the UPGMA method (Sneath and Sokal, 1973)

\begin{tabular}{|c|c|c|c|c|c|c|c|c|c|c|}
\hline Species & 1 & 2 & 3 & 4 & 5 & 6 & 7 & 8 & 9 & 10 \\
\hline 1 & - & 0.091 & 0.091 & 0.091 & 0.073 & 0.091 & 0.091 & $0 \cdot 091$ & 0.091 & 0.048 \\
\hline 2 & 0.085 & - & 0.060 & 0.072 & 0.091 & 0.072 & 0.072 & 0.072 & 0.085 & 0.091 \\
\hline 4 & 0.092 & 0.048 & 0.066 & - & 0.091 & 0.044 & $0 \cdot 044$ & 0.044 & 0.085 & 0.091 \\
\hline 5 & 0.048 & 0.092 & 0.112 & 0.099 & - & 0.091 & 0.091 & 0.091 & 0.091 & 0.073 \\
\hline 6 & $0 \cdot 085$ & 0.085 & 0.060 & 0.023 & 0.092 & - & 0.023 & 0.023 & 0.085 & 0.091 \\
\hline 9 & 0.085 & 0.085 & $0 \cdot 106$ & 0.092 & 0.092 & 0.085 & 0.092 & 0.048 & - & 0.091 \\
\hline 10 & 0.048 & 0.092 & $0 \cdot 112$ & 0.099 & 0.099 & 0.092 & $0 \cdot 054$ & 0.099 & 0.092 & - \\
\hline
\end{tabular}



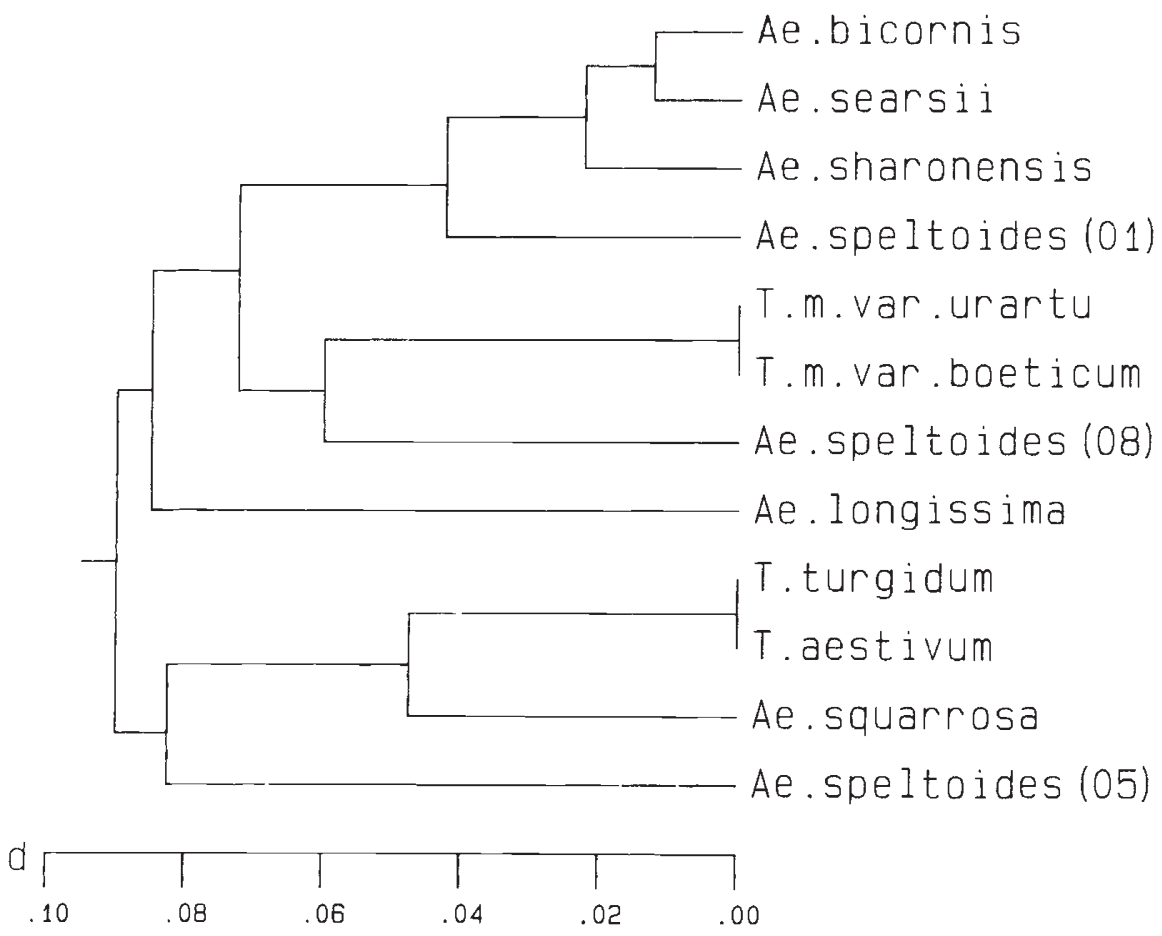

Figure 3 Mitochondrial phylogenetic tree for Triticum and Aegilops species. $d=$ the number of nucleotide substitutions per site as estimated according to Nei and $\mathrm{Li}$ (1979). The dendrogram was derived by using the UPGMA clustering method (Sneath and Sokal 1973).

subsequently used to construct a UPGMA phylogenetic tree (Sneath and Sokal, 1973). The resulting tree is presented in fig. 3. We observe no clear taxonomic distinction between the two genera, Triticum and Aegilops. Consequently, our results agree with several suggestions in the literature (e.g., Bowden, 1959) that all wheat species should be included in the genus Triticum.
In fig. 4 we present the expected maternal phylogenetic relationships between the different genomes. Since the hexaploid AABBDD genome is derived on the maternal side from $\mathrm{AABB}$, it is expected that the two species closest to each other in terms of their mitochondrial constitution should be $T$. aestivum and T.turgidum. This is indeed the case (fig. 3). The next in line should be the yet

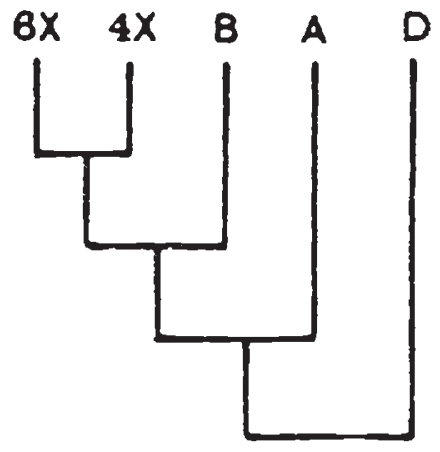

(1)

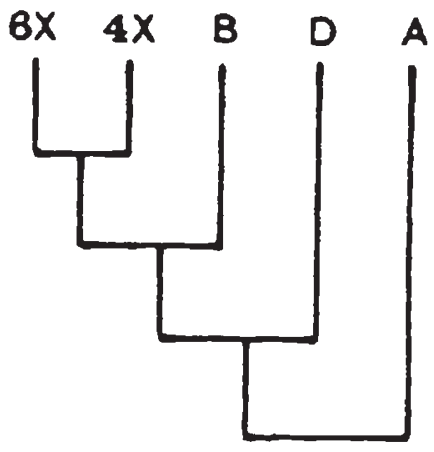

(2)

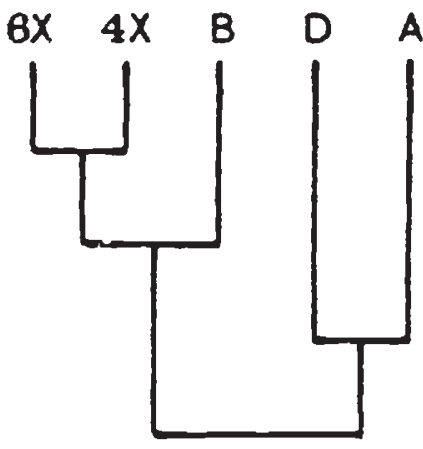

(3)

Figure 4 Expected mitochondrial phylogenetic relationships between the A, B and D diploid genomes and the tetraploid (4X) and hexaploid $(6 \times)$ genomes of wheats. (1) represents the case where A is closer than D to the hexaploid matriline, (2) represents the opposite case, and (3) represents the case where A and D are equidistant from the hexaploid matriline. 
unknown BB donor, which is the maternal ancestor of AABB. Further removed we should find DD (Ae. squarrosa) and AA ( T. monococcum), which are not related to the maternal side of either AABB or AABBDD. None of the species in our study, which have been previously suspected of being the donor of the B genome, is more closely related to Triticum than Ae. squarrosa, which by virtue of its being the donor of the $\mathrm{D}$ genome presumably cannot also be the donor of B. In fact, only one accession of Ae. speltoides (05) is closer to Triticum than $T$. monococcum, but it too is more distant from Triticum than Ae. squarrosa. In other words, we can exclude all the species in this study from the list of potential donors of the B genome; none of them is the Grandmother-of-Wheat. This conclusion depends neither on the choice of distance measure nor on the method of reconstructing the topology of the tree. By using any of the pertinent parsimony methods included in the PHYLIP package (kindly provided by $\mathrm{Dr}$ J. Felsenstein), we obtain very similar trees, regardless of whether we use character or distance measures. This finding agrees with Kerby and Kuspira's (1987) compilation of evidence that excludes all the above species as the $\mathrm{B}$ donors to the polyploid wheats.

In regard to the more distant relationships, there are three possible topologies that are consistent with the geneology presented in fig. 1: (1) $A A$ is more closely related than DD to the AABBDD matriline, (2) DD is closer to AABBDD than AA, and (3) AA and DD are equidistant from AABBDD. These possibilities are illustrated in fig. 4. Our results show that Ae. squarrosa is closer to the Triticum maternal lineage than both subspecies of $T$. monococcum, supporting hypothesis (2).

Ogihara and Tsunewaki (1982) and Tsunewaki and Ogihara (1983) found that the restriction pattern of chloroplast DNA from $T$. turgidum ( $T$. dicoccoides and $T$. dicoccum in their notation) was identical with that of Ae. longissima. Since chloroplast DNA is also maternally inherited, their conclusion was that Ae. longissima is the donor of the $B$ nuclear genome. They reasoned that while the nuclear genome changed rapidly since the time of divergence, the chloroplasmic genome did not change much, and we should rely on chloroplast data to reconstruct the maternal phylogeny of wheat. While it is certainly correct that in plants chloroplast DNA evolves much slower than nuclear DNA, it is also true that the rate of evolution of plant mitochondrial DNA is less than one third that of chloroplast DNA (Wolfe et al., 1987). Since (1) mitochondrial DNA is more conservative than chloroplast DNA, and (2) chloroplast DNA restriction enzyme patterns of $T$. aestivum and $A e$. longissima are indistinguishable (Tsunewaki and Ogihara 1983), it is expected that the mitochondrial DNA patterns from these two species should also be identical. This expectation is not confirmed by the observations presented here. In addition, Tsunewaki and Ogihara's identification of Ae. longissima as the donor of the B genome is not corroborated by the findings of Bowman et al. (1983), in which the chloroplasts of other species, such as Ae. speltoides, could not be excluded from the list of suspects. The discrepancies between the banding patterns of chloroplast DNA in these two studies may be attributed to the intraspecific variation in Ae. longissima chloroplasts, or to the possibility that Bowman et al. happened to choose more variable restriction sites than did Tsunewaki and Ogihara. Terachi et al. (1985) found that mitochondrial DNA from Ae. longissima gives identical restriction patterns with that from $T$. aestivum.

In light of the findings presented here and previous findings by other authors, we are left with several alternatives concerning the identity of the B-donor:

(1) The donor of $\mathrm{B}$ is a diploid species that has not been discovered yet, or that became extinct.

(2) The B donor is a species with high levels of mitochondrial polymorphism, e.g., Ae. speltoides. Thus, identifying the donor would require the study of many accessions from each such species.

(3) The B donor is a species that is usually not included in traditional lists of suspects. For instance, in the study of Bowman et al. (1983), the restriction patterns of chloroplast DNA from two accessions of $T$. timopheevi (section Dicoccoidea) are more similar to that of polyploid wheats than that of members of the Sitopsis section. This alternative also includes the possibility that the B genome is of polyphyletic origin (first suggested by Sarkar and Stebbins, 1956), or that the B genome was not derived from a diploid species.

(4) The $B$ donor has not retained its original mitochondria due to introgression of mitochondrial DNA from a different species (e.g., Ferris et al., 1983; Powell, 1983; Spolsky and Uzzell, 1984).

(5) The present mitochondria of the B donor has lost all similarity to the mitochondria of $\mathrm{B}$ in the past through extensive intramitochondrial recombination processes and internal rearrangements (e.g., Falconet et al., 1984). These processes are not expected to affect the 
DNA sequence, but are expected to greatly affect restriction enzyme patterns. This possibility would explain why mitochondrial genomes show higher variability in their restriction endonuclease profiles than chloroplast genomes.

(6) The most radical departure from traditional thinking would be to assume that Ae. squarrosa, the donor of the D genome or one of its close relatives, Ae. cylindrica or Ae. ventricosa, was also the donor of B. In other words, to assume that the B and D genomes are distantly related with each other, having diverged considerably from the time of introduction of the B genome into $T$. turgidum until a much later time, in which the B-turned-D genome was introduced into T. aestivum. This possibility is consistent with existing empirical data, but it has not been tested yet.

Acknowledgments We wish to thank Drs $\mathrm{M}$. Nei and $\mathrm{K}$ Tsunewaki for many pertinent suggestions. Mr Robert Schwartz kindly helped us with the figures. Part of this work was supported by the Foundation for Basic Research, the Israeli National Academy of Sciences (A.B.) and the Hertz Foundation (D.G.)

\section{REFERENCES}

AARONSOHN, A. 1906. Die auffindung des wilden emmers (Triticum dicoccum) in Nordpalästina. Altneuland, 3, 213216.

AARONSOHN, A. 1909. Contribution à l'histoire des céréales, le blé, l'orge et le seigle à l'état sauvage. Bull. Soc. Bot. France, 56, 196-203.

ANIKSTER, Y. AND WAHL, 1. 1979. Coevolution of the rust fungi on Gramineae and Liliaceae and their hosts. Ann. Rev. Phytopathol., 17, 367-403.

BOWDEN, W. M. 1959. The taxonomy and nomenclature of the wheats, barleys and ryes and their wild relatives. Can. $J$. Bot., 37, 657-684.

BOWMAN, C. M., BONNARD, G. AND DYER, T. A. 1983. Chloroplast DNA variations between species of Triticum and Aegilops. Location of the variation on the chloroplast genome and its relevance to the inheritance and classification of the cytoplasm. Theor. Appl. Genet., 65, 247-262.

BREIMAN, A. 1987. Mitochondrial DNA diversity in the genera Triticum and Aegilops revealed by Southern blot hybridization. Theor. Appl. Genet., 73, 563-570.

CHEN, K., GRAY, J. C. AND WILDMAN, S. G. 1975. Fraction I protein and the origin of polyploid wheats. Science, 190, 1304-1306.

DE CANDOLle, A. 1883. Origine des Plantes Cultivées. Paris.

FALCONET, D., LEJEUNE, B., QUETIER, F. AND GRAY, M. W. 1984. Evidence for homologous recombination between repeated sequences containing $18 \mathrm{~S}$ and $5 \mathrm{~S}$ ribosomal RNA genes in wheat mitochondrial DNA. EMBO J., 3, 297-302.
FELDMAN, M. 1978. New evidence on the origin of the B genome of wheat. In Proceedings of the 5th International Wheat Genetics Symposium, Indian Academy of Science, New Delhi, pp. 120-132.

FERNANDEZ DE CALEYA, R., HERNANDEZ-LUCAS, C., CARBONERO, P. AND GARCIA-OLMEDO, F. 1976. Gene expression in allopolyploids: genetic control of lipopurothionins in wheat. Genetics, 83, 687-699.

FERRIS, S. D., SAGE, R. D., HUANG, C. M., NIELSEN, J. T., RITTE, U. AND WILSON, A. C. 1983. Flow of mitochondrial DNA across a species boundary. Proc. Natl. Acad. Sci. USA, 80, 2290-2294.

GERLACH, W. L., APPELS, R., DENNIS, E. S. AND PEACOCK, W. J. 1978. Evolution and analysis of wheat genomes using highly repeated DNA sequences. In Proceedings of the 5th International Wheat Genetics Symposium, Indian Academy of Science, New Delhi, pp. 81-91.

GILL, B. S. AND KIMBER, G. 1974. Giemsa C-banding and the evolution of wheat. Proc. Natl. Acad. Sci. USA, 71, 40864090.

HARLAN, J. R. AND ZOHARY, D. 1966. Distribution of wild wheats and barley. Science, 153, 1074-1080.

HELBAEK, H. 1959. Domestication of food plants in the Old World. Science, 130, 365-371.

HIRAI, A. AND TSUNEWAKI, K. 1981. Genetic diversity of the cytoplasm in Triticum and Aegilops. VIII. Fraction I protein of 39 cytoplasms. Genetics, 99, 487-498.

JAASTA, V. 1978. NADP-dependent aromatic alcohol dehydrogenase in polyploid wheats and their diploid relatives On the origin and phylogeny of polyploid wheats. Theor. Appl. Genet., 53, 209-217.

JENKINS, J. A. 1966. The origin of cultivated wheat. Can. $J$. Genet. Cytol., 8, 220-232.

JOHNSON, B. L. 1972. Protein electrophoretic profiles and the origin of the B genome of wheat. Proc. Natl. Acad. Sci. USA, 69, 1398-1402.

JOHNSON, B. L. 1975. Identification of the apparent B-genome donor of wheat. Can. J. Genet. Cytol., 17, 21-39.

JONES, B. L., LOOKHART, G. L., MAK, A. AND COOPER, D. B 1982. Sequences of purothionins and their inheritance in diploid, tetraploid and hexaploid wheats. J. Hered., 73, 143-144.

KERBY, K. AND KUSPIRA, J. 1987. The phylogeny of the polyploid wheats Triticum aestivum (bread wheat) and Triticum turgidum (macaroni wheat). Genome, 29, 722-737.

KIHARA, H. 1919. Über cytologische Studien bei einigen Getreidearten. Mit. I. Spezes-bastard des Weizen und Weizenroggen-bastarde. Bot. Mag., 33, 17-38.

KIHARA, H. 1924. Cytologische und genetische Studien bei wichtigen Getreidearten mit besonderer Rücksicht auf das Verhalten der Chromosomen und die Sterilität in den Bastarden. Mem. Coll. Sci. Kyoto Imp. Univ., 1, $1-200$.

KIHARA, H. AND LILIENFELD, F. A. 1951. Genome-analysis in Triticum and Aegilops. X. Concluding review. Cytologia, $16,177-193$

KIMBER, G. AND SEARS, E. R. 1983. Assignment of genome symbols in the Triticeae. In Proceedings of the 6th International Wheat Genetics Symposium, Kyoto, Japan, pp. 1195-1196.

KUSHNIR, U. AND HALLORAN, G. M. 1981. Evidence for Aegilops sharonensis Eig as the donor of the B genome of wheat. Genetics, 99, 495-512.

MAAN, S. S. AND LUCKEN, K. 1967. Interaction of Triticum boeoticum cytoplasm and genomes of $T$. aestivum and $T$. durum: Restoration of male fertility and plant vigor. Euphytica, 19, 498-508. 
MAAN, S. S. AND LUCKEN, K. 1971. Nucleo-cytoplasmic interactions involving Aegilops cytoplasms and Triticum genomes. J. Hered., 62, 149-152.

MORRIS, R. AND SEARS, E. R. 1967. The cytogenetics of wheat and its relatives. In Quinsenberry, K. S. and Reitz, L. P. (eds.) Wheat and Wheat Improvement, American Society of Agronomy, Madison, Wisconsin, pp. 19-87.

NEI, M. 1987. Molecular Evolutionary Genetics. Columbia University Press, New York.

NEI, M. AND LI, W-H. 1979. Mathematical model for studying genetic variation in terms of restriction endonucleases. Proc. Natl. Acad. Sci. USA, 76, 5269-5273.

OGIHARA, Y. AND TSUNEWAKI, K. 1982. Molecular basis of the genetic diversity in the cytoplasm in Triticum and Aegilops. I. Diversity of the chloroplast genome and its lineage revealed by the restriction pattern of ctDNA. Jpn. J. Genet., 57, 371-396.

POWELL, J. R. 1983. Interspecific cytoplasmic gene flow in the absence of nuclear gene flow: evidence from Drosophila. Proc. Natl. Acad. Sci. USA, 80, 492-495.

REES, H. AND WALTERS, M. R. 1965. Nuclear DNA and the evolution of wheat. Heredity, 20,73-82.

RILEY, R., UNRAU, J. AND CHAPMAN, V. 1958. Evidence on the origin of the B genome of wheat. J. Hered., 49, 91-98.

SAKAMURA, T. 1918. Kurze Mitteilung über die chromosomenzahlen und die Verwandschaftsverhältnisse der TriticumArten. Bot. Mag. Tokyo, 32, 150-153.

SARKAR, P. AND STEBBINS, G. L. 1956. Morphological evidence concerning the origin of the B genome in wheat. Amer. $J$. Bot., 43, 297-304.

SEARS, E. R. 1956. The B genome of Triticum. Wheat Inf. Serv., $4,8-10$.

SNeATH, P. H. A. AND SOKAL, R. R. 1973. Principles of Numerical Taxonomy. Freeman, San Francisco.
SPOLSKY, C. AND UZZELL, T. 1984. Natural interspecies transfer of mitochondrial DNA in amphibians. Proc. Natl. Acad. Sci. USA, 81, 5802-5805.

STERN, D. B. AND LONSDALE, D. M. 1982. Mitochondrial and chloroplast genomes of maize have a $12 \mathrm{~kb}$ DNA sequence in common. Nature, 229, 698-702.

TERACHI, T., OGIHARA, Y. AND TSUNEWAKI, K. 1985. Mitochondrial DNA diversity among Triticum and Aegilops species. Wheat Inf. Service, 60, 35-36.

TSUNEWAKi, K. AND OGIHARA, Y. 1983. The molecular basis of genetic diversity among cytoplasms of Triticum and Aegilops species. II. On the origin of polyploid wheat cytoplasms as suggested by chloroplast DNA restriction fragment patterns. Genetics, 109, 155-171.

VEDEL, F., QUETIER, F., DOSBA, F. AND DOUSSINAULT. 1978. Study of wheat phylogeny by EcoRI analysis of chloroplasmic DNAs as genetic markers. Theor. Appl. Genet., 59, 239-245.

VITTOZi, L. AND SILANO, V. 1976. The phylogenies of protein $\alpha$-amylase inhibitors from wheat seed and the speciation of polyploid wheats. Theor. Appl. Genet., 48, 279-284.

WOLFE, K. H., LI, W. H. AND SHARP, P. M. 1987. Rates of nucleotide substitution vary greatly among plant mitochondrial, chloroplast, and nuclear DNAs. Proc. Natl. Acad. Sci. USA, 84, 9054-9058.

ZOHARY, D. 1965. Colonizer species in the wheat group. In Baker, H. G. and Stebbins, G. L. (eds.) The Genetics of Colonizing Species, Academic Press, New York, pp. 403419.

ZOHARY, D. 1983. Wild genetic resources of crops in Israel. Israel J. Bot., 32, 97-127. 